\title{
Reservation Policy and Indian Society: Its Practical Obligation
}

\author{
Hema Bannerjee $^{1^{*}}$ and Swapan K Biswas ${ }^{2}$
}

${ }^{1}$ Department of Economics, Jawaharlal Nehru Rajkeeya Mahavidyalaya, PG College, Port Blair, India

${ }^{2}$ PG Dept. of Political Science, Jawaharlal Nehru Rajkeeya Mahavidyalaya, PG College, Port Blair, India

*Corresponding author: jeet06123@ rediffmail.com

Received: 15-11-2019 Revised: 07-02-2020 Accepted: 30-03-2020

\begin{abstract}
Agitation over the implementation of Mondal Commission reservation policy in Indian states \& union in education \& jobs was also a reality in early nineties a section of the prominent Indian are against the reservation. Their opinion is that the present government must think seriously about reconsideration of reservation benefits enjoying by a section of Indian. After implementation of $27 \%$ reservation to the notified castes and communities in all religions, around $97 \%$ of all jobs and admission in educational institutions at the Central establishments for OBC has gone to 656 sub caste out of 2633 notified OBC castes under Central notified castes /classes. In the A \& N islands the inclusion of the communities in the ambit of $\mathrm{OBC}$ reservation is something unique. The islands society is a casteless and classless society. Now granting of reservation for economically poor within the upper castes by $124^{\text {th }}$ Amendment of Constitution has further diluted the caste discrimination. Those were strongly against the any kind of quota system are now agitating for reservation benefits i.e. quotas for "us" are always justified. Every section of the society wants to get the benefit of reservation by forgetting their caste hierarchy. However, the case of receiving the benefit of reservation by dominant class or upper castes would never eliminate discrimination of caste hierarchy from Indian society.
\end{abstract}

Keywords: Mondal Commission, Muddled thinking, Pattidar movement, Justice G. Rohini Commission, Son of the Soil

Indian Union cabinet has announced $10 \%$ reservation for economically backward groups in the upper castes is not a surprise but a reality. The polity and social system, reservation \& castes is complementary to each other. It is a continuous process to add and add in the policy of reservation. Some new groups play political games, especially when election is at the doorstep. Agitation over the implementation of Mondal Commission reservation policy in Indian states \& union in education \& jobs was also a reality in early nineties. It is true, the scope of job in government sectors is slowdown. No government gets success to implement job reservation in private sectors. Whatever, limited jobs are created in government sectors is not enough for all sections of the people. Present general education system is not fit for new and global level technical \& professional jobs. Majority of the Indian receiving the education, which is not enough for present in the competitive jobs market. Job market is stagnant. The Pattidar movement has revealed that the traditional family business or farming land is not ensuring the present generation about their changing mind towards white colour jobs. Reservation in education and later in job is only option for present generation as it is enjoying by communities under reservation. The growing demand for reservation of upper dominating castes like Jats, Maraths and Patels in their respective states is playing a serious challenges in state politics and Union too.

It also revealed from pattidar movement that, the young jats, Patels, Kapus and Marathas of dominants castes, who fail to get good jobs in the private sectors fall back on the govts. "parents of girls prefer grooms with stable income - those with government jobs are often their preferred choice." ${ }^{11}$ 
However, a section of the prominent Indian are against the reservation. Their opinion is that the present government must think seriously about reconsideration of reservation benefits enjoying by a section of Indian.

\section{Benefits of Reservation after three decades}

The Union government is already in the deep of OBC reservation after implementation in early nineties. The present Union Govt. has set up a Commission, headed by former Chief Justice of Delhi High Court, Justice G. Rohini in October 2017. The commission sent it's first phase finding to all Chief Secretaries of States \& Union Territories. The major findings of the Commission is so surprising and against the basic policy of Social equality \& justice. The Mondal commission reservation was operationalized among more than 2633 castes and sub-castes and to extend the ambit the benefit of reservation in education and jobs for these vast left out communities.

But after implementation of $27 \%$ reservation to these notified castes and communities in all religions, around $97 \%$ of all jobs and admission in educational institutions at the Central establishments for OBC has gone to 656 sub caste out of 2633 notified OBC castes under Central notified castes /classes. Remaining $2.68 \%$ jobs and educational reserve seats shared by 994 (37\%) sub-castes and surprisingly 983 (36\%) OBC communities did not shared a single jobs and admissions. It is found that reservations fruits have gone to limited communities or prime beneficiaries are Yadav, Kurmi, Jats (Jats of Rajasthan except Bharatpur and Dholpur districts) and Saini in Northern parts of Hindi belt and Theva, Ezhava and Vokakaliga of Southern Indian States. ${ }^{2}$

According to the report 1.3 lakh jobs given under Central services for $\mathrm{OBC}$ and admission to primer institutions including universities, IITs, IIMs, NIT AIIMS for last three years. The reports from data reveals that the share of OBC benefits of several states is much higher than their share of populations of India. Whereas, there are many states with much lower share in reservation benefits than their share of population. (ibde).

In this regards many states have adopted some kind of sub-categorization in their OBC lists. However, none of the state/UTs seems to have proposed any clearly articulated criterion for placing a community in one category or other.

\section{Reservation policy in West Bengal; some valid questions}

In West Bengal, the Kaka Kalelkar Commission in 1953 identified only three Muslim Community under OBC category. However, it is pertinent to mention that Mondal Commission report has identified 177 community in West Bengal under OBC. Of which only 04 Muslim Community were included in this benefit. During Left Front regime, 68 communities were enlisted under OBC, of which only 08 Muslims Community were included .But the present ruling government TMC has categories the OBC list into two groups : Most Backward Class Category -A and Backward Class, category -B. In the $\mathrm{MBC}-\mathrm{A}, 81$ communities were included, all are Muslim .Subsequently, in BC -B category 40 Muslim community are included for the OBC benefits in West Bengal Education and jobs. Which is defined by opposition as Muslim appeasement politics of present government. ${ }^{3}$

The present addition of upper caste in the orbit of reservation, who are defined economically backward by Central Cabinet is a new dimension in the reservation policy. According to Social Scholar like Pratap Bhanu Mehta "by including upper castes under the sign of reservation, it dissociates caste and the stigma of reservation. Upper caste can no longer resent Dalits and others for reservation. Dalits groups have been arguing this for a while; hence their support for this policy" ${ }^{\prime \prime}$. The Cabinet decision to extend $10 \%$ reservation to economically weaker section of upper castes will open up the states to another set of demands raised from dominant castes like Jats, Maraths and Patels. ${ }^{5}$

\section{Reservation policy in Islands Society}

Along with rest of India, A \& $\mathrm{N}$ islands, the Union Territory also implemented Mondal Commission reports. Hence, the UT administrator, Lt. Governor issued a notification in 1994 for setting up six members Committee including a Chairman. The Commission had set various criteria for inclusion of communities in the OBC group. As per the Committee reports and recommendation, the families who had settled before 1942 by the British under Penal settlement/colonization scheme 
and post independence, Government of Indian rehabilitation scheme after 1949 (read only Bengali migrated from erstwhile East Pakistan at the time of partition of India) and their decedents has been defined as "Son of the Soil" and socio-economically backward, who were eligible for OBC benefits.

The A \& N OBC commission had submitted its reports in July 2001 to the UT administration. Accordingly, the A \& N Administration published gazette notification No.354/Dec/16, 2005 in which following communities were included in $\mathrm{A} \& \mathrm{~N}$ OBC list: ${ }^{\circ}$

\section{(A) Pre-1942 settlers comprising.}

1. Local Born, 2. Bhantus, 3. Moplas, 4. Karen and

(B) Post - Independent Settlers i.e. from 1949.

\section{Bengali}

The Commission,in its supplementary reports recommended $38 \%$ reservation in jobs for $\mathrm{A} \& \mathrm{~N}$ OBC beneficiaries.

The OBC commission cited the parameter to identify the backwardness of the certain communities in the islands. The guidelines were economic condition of the community, Occupation -cum-income factor, educational standard etc. The inclusion of the communities in the ambit of $\mathrm{OBC}$ reservation is something unique. The islands society is a casteless and classless society. The pre- independent settlers set a casteless society irrespective of their mother tongue, provincial identity \& religious practices. All are recognized as decedent of Local Born community. It is the composition of all caste, sub-caste, community and religion without any separate identification.Apart from that the small community like Bhantu, Burmese, Karen are also the part of Pre-1942 settlers. The post independent settled community is Bengalee (under OBC reservation benefit), who are majority in terms of population. All Bengalee settlers are recognized as one community irrespective of their caste, subcaste identity. The $\mathrm{OBC}$ benefits are enjoying by all Bengalee settlers, where Brahmin, Khayasta, Baishya and Sudra are co-existing. Among other community of Pre- 1942 settlers, the Muslim, Christain, Sikh, Brahmin, Khatriya, Thakur, Sudras and other unidentified sub-castes are equally benefited of the OBC reservation.
However, over the time, the operational part of the $\mathrm{OBC}$ benefits is not satisfying the Bengalee, the major community, who are living in isolated and far flung islands. The education, economic condition, job opportunity, occupation \& place of residence of two different class of people (City \& rural islands) are completely different. Therefore, benefits of reservation is enjoying by the well settled, city based 'Local born \& Moplas communities'. Hence, the Bengalee, Small community like Karen and Bhantus are depriving. ${ }^{7}$ The Karen being a tiny group (Approx.3000 only) living in North Andaman without receiving basic facilities are dissatisfied to placed them under OBC category. The Karen Youth Organizations have already given their representations before Union Govt. and Local administration with the demand that they have to be given Tribal status as they are the decedent of tribal community in Burma (Myanmar). However, over last two decades, neither Union Govt. nor Local Administration look after their lawful genuine demand.

It is the opinion of the renowned legal expert like Faizan Mustafa most reservation schemes have been announced on the eve of general election or assembly elections too ${ }^{8}$. According to him that the recent announcement of Modi govt. regarding the inclusion of economically weaker section of upper castes in the ambit of reservation will be defeated in the test of judicial processes. The finding of the a nine -judge bench in Indira Sawhney case said that reservation is not aimed at economic uplift or poverty alleviation. Economic backwardness is to be on account of social backwardness. Hence, it is clear that social deprivation and discrimination is the ultimate cause of economic deprivation and backwardness.

Similarly, noted Economist \& Noble Laurite Prof. Amartya Sen described the proposed 10\% reservation for the economically backward among the general castes as an outcome of "muddled thinking". It will be raised question about its impact on political and economy of the country. According to his opinion "reservation for low income upper caste (people) is a different problem. If the whole of the people is covered by reservation then that would be removal of reservation". ${ }^{9}$ 


\section{Remarks on Reservation}

Social discrimination based on caste is a solid rock and reality in Indian society. Reservation to SCs \& STs for their up-leftment both economically and socially is a constitutional commitment. To eliminate social discrimination, the benefit of reservation has been introduced. The availing of reservation benefit has created social division in educational institutions by creating separate seating arrangement and to some extend mid-day meal also served separately in school premises is an instance of growing caste discrimination or victim of caste in modern Indian Society. Availing of quota reservation system is so deep and give serious impact on educational institutions and job places who are facing discrimination constantly. Distinction has made between two class of students \& employees by defining them as "Sonar Chand" for SCs and "Sonar Tukra" for STs in Eastern part of India. After Mondal Commission OBC reservation, a larger section of the population has come under the orbit of Quota benefit, the distinction has been diluted. Now granting of reservation for economically poor within the upper castes by $124^{\text {th }}$ Amendment of Constitution has further diluted the caste discrimination as feel by Riya Kushwaha, a Ph.D student, who is covered by the OBC quota. She said "Invariably upper caste students would taunt us saying 'Oh, you have come through a quota'. Now that they are also in that line, at least they will stop taunting us". ${ }^{10}$

The implementation of Kaka Kalelkar Commission in 1953 and Mondal commission reports on reservation of $\mathrm{OBC}$ has extended the orbit of further resent among communities who are not receiving the benefit of reservation. The Gujjar, Jat, Maratha movements in different states are indication of extending reservation for other castes also. If every community is demanding for separate reservation benefits, than there is no question of social division. Who are coming under the ambit of reservation irrespective of caste and religion must have to be treated as one group. Than we must accept the idea of Prof. Sen if the whole of the people is covered by reservation then that would be removal of reservation. That means removal of social discrimination among all caste and community. Let us distribute the all share of jobs and admission among all community as per their population ratio irrespective of social division. Secondly, who have enjoyed the benefit of reservation in education and services and got comfortable position, their name should be eliminated from the list of reservation in the name of "Creamy layer". Thirdly, irrespective of income, the first general of OBC should be given benefit of reservation. In case of Andaman, for the first time the OBC reservation policy has been introduced in 2006. However, due to implementation of "Creamy Layer" on the basis of income of the spouse, many of the government employees deprived of from the benefit of the $\mathrm{OBC}$ quota for their children who never enjoy the benefit of the OBC reservation of any generation.

Prof. Satish Deshpande rightly said that Quotas for "them" are always suspect, but quotas for "us" are always justified, because the issue is not quota but caste, "ours" and "theirs". After independence, reservation for SCs \& STs was undigested for rest of non-reserved groups, when Mandal Commission extended benefits of a larger section of people, the beneficiaries of the new quotas become the supporter of reservation. But those were strongly against the any kind of quota system are now agitating for reservation benefits i.e. quotas for "us" are always justified. Every section of the society wants to get the benefit of reservation by forgetting their caste hierarchy. However, the case of receiving the benefit of reservation by dominant class or upper castes would never eliminate discrimination of caste hierarchy from Indian society. According to Prof. Deshpande "But lower caste people continue to face social discrimination in different ways no matter how rich they become - for example, they may find it difficult to rent an apartment or join a club. And they often face discrimination within their own class. Thus, lower caste IAS officers, corporate executives, doctors and professors have been documented as facing subtle yet debilitating forms of discrimination from their peers."11

At present situation, when job is almost in a stagnant position, of which 3-4 \% jobs hardly come under reservation contour. As Prof. Deshpande rightly explained that grain of jeera in the mouth of the camel. For whom all sections of the people of the society are demanding a small percentage of share from the reservation quotas. 


\section{CONCLUDING REMARKS}

If you go for reaction of the political parties. The Congress party, the main opposition have called this move an election gimmick as the Supreme Court has already ruled that not more than 50 per cent of reservations can be provided in jobs or in education. Kancha Ilaiah Shepherd, a prominent thinker on caste issues support the move of the present government and also said English education throughout India for all section of the people can resolve the competition in the job markets. According to him, among the Muslim, the children of the eliteintellectuals class study in English and higher education from three prominent universities which are strictly giving modern education. However, the children of the poor Muslim study state run Urdu medium schools or in Madrasas. He is in favour of children of all section /classes should impart English medium education run by the both Union and states Governments at schools and Higher education levels. Uniform English education for all section of the people is the only option to make the children for a better competition in the job markets. ${ }^{12}$

The constitutional amendment of $10 \%$ quota reservation for EWS of the upper castes in jobs and education has ultimately open the doors of other communities, who are constantly demanding and agitating for their reservation in public jobs and seats in education. The Gujjar movement for considering their community as Tribes. Dominating agrarian community like Jats, Marathas, Patels are now getting excuse for their yearlong demands for separate quotas. The leaders of the dominating Jats community has already given ultimatum to the ruling BJP government at center that their community will vote against the ruling party in the upcoming elections unless their demand for reservation is not accepted. They said that government had cheated the community by not accepting its demand for quota and giving forward castes $10 \%$ reservation "within seven days". Other hand like Gujjar in Rajesthan, Dhangar Community in Maharastra has given an ultimatum to the state govt. To consider its long pending demand for reservation under ST category instead they have given Nomadic Tribes (C) category, which comes under $\mathrm{OBC}$ category.

Justice G. Rohini commission has come out with the suggestion regarding $\mathrm{OBC}$ sub-quota that recommended a fixed quota, possibly between $8-10 \%$ within the $27 \%$ OBC quota for members of 1900 -odd castes from among the 2633 central list. As per its observation half of the 1900 odd- castes have availed less than $3 \%$ of reservation in jobs and education and rest availed zero benefits during five years. The significant recommendation of the Commission is that the classification is based on relative benefits availed and not on relative social backwardness, which involves parameters such as social status, traditional occupations, religions etc. The Commission stated that "OBCs have been defined already using a social criteria, we are not going to create social hierarchy among backward classes .Several of these 1900 groups may have been unable to avail the benefit of reservation only because they are miniscule in numbers and this restricts their access to education and jobs. To correct this inequity of benefits accrued, the commission is likely to suggest that of the $27 \%$ quota, a fixed $8-10 \%$ be reserved for such groups. This comes to merely 2-3\% of the total OBC quota and would not affect other groups but will create substantial opportunities for those left all this while. The commission further stated that, "If we able to ensure a fixed reservation for these groups in elite educational institutions such as IITs \& IIMs or within the IAS or IPS, it would mean a lot for them". ${ }^{13}$

\section{REFERENCES}

Christophe Jaffrelot. 2016. Indian Express, Everyone wants a quota, 23/02/2016, pp. 9.

Justice Rohini, G. 2019. Commission Recommendation Report: Jobs, Admission: 97\% of Central OBC quota benefits go to under $25 \%$ of its castes, Indian Express (Kolkatta), 8/12/2018, pp.1.

Baidya, Nikhil. 2018. Chilo -rumal -hoya-giloo-Biral ...Aar par Kee (In Bengali) in Bag-Pratima -Durga Puja issue, 1425/2018.

Mehta, Pratap Bhanu. 2019. The Reservation Jumla, Quota for upper caste poor is cynical .........Indian Express, 8/1/2019

Indian Express: The 10\% Answer, Editorial Column, about reservation, 8/1/2019.

Andaman \& Nicobar OBC notification No.354/Dec/16, 2005.

Bannerjee, Hema. 2009. Reservation Policy; A controversial affairs in Islands society, IJPS, vol. LXX (3), Sept. 2009, p.816.

Mustafa, Faizan. 2019. Slipping on Quota : why reservation for economically a backward ........ Indian Express, 9/1/2019 
Sen, Amaryta. 2019. 'Muddled' tag on quota, 10/01/2019, The Telegraph, Kolkata.

Deshpande, Satish. 2019. Quotas, theirs \& ours : Being the poor is different from belonging to lower castes Indian Express, 11/1/2019, p.6
Ibid: Prof. Satish Deshpande.

www.Rediff.com.KanchaIlaiah Shepherd, (7/1/2019) tells Syed Firdaus Ashraf.

Justice G. Rohini. 2019. Commission panel Recommendation Report : Panel Recommendation, IE, 08.05.19. 